\title{
Investigation of UV exposure in adhesively bonded single lap joints
}

\author{
F. C. Amorim ${ }^{1,2}$, J. M. L. Reis ${ }^{1 *}$ (D, J. F. B. Souza ${ }^{1}$ and H. S. da Costa Mattos ${ }^{1}$
}

*Correspondence:
jreis@id.uff.br
${ }^{1}$ Laboratory of Theoretical
and Applied Mechanics,
Graduate Program
in Mechanical Engineering,
Universidade Federal
Fluminense, Rua Passo
da Pátria 156, Niterói, RJ
$24210-240$, Brazil
Full list of author information
is available at the end of the
article

${ }^{*}$ Correspondence:

and Applied Mechanics,

Graduate Program

Universidade Federal

Fluminense, Rua Passo

Full list of author information

article

\begin{abstract}
Adhesively bonded joints are being widely used in the fabrication process of aircraft and automobile structures. Surface roughness is an important parameter of product quality that strongly affects the performance of mechanical parts, as wel as production costs. This parameter highly influences the mechanical properties overall of such structures. The effects of UV radiation on the single lap joints manufactured with different types of surface preparation and temperature were examined before and after UV exposure. Sandblasting, sanding and chemical cleaning were used as surface preparation and two test temperatures were used for investigation, 25 and $115^{\circ} \mathrm{C}$. The results of those tests showed that surface preparation highly influences shear strength, but does not affect the stiffness of the tested joints. Temperature also influences the shear strength and stiffness. UV radiation contributes to increase shear strength and do not degrade the tested single lap joints.
\end{abstract}

Keywords: Epoxy, Single lap joints, UV exposure, Shear strength

\section{Background}

In recent decades adhesively bonded joints gained attention in many industries such as automotive, aeronautics and offshore, increasing structural mechanical repair services and thus promoting technological advances. It is a trend to nowadays replace welded and bolted joint for adhesively bonded joint. Advantages over welded and bolted joints are don't need a fire exposure, fast manufacturing, fatigue and corrosion resistance. Although the geometry of bonded joint is complex considering particularities at the end of joint, adhesive joint promotes a decrease of stress concentration [1, 2].

A relation between adherend and adhesive material and consequently the load transfer of joint is intrinsically related to surface state. The correct preparation requires total removal of contaminants (remaining corrosion layers, dirt, lubricating and bio-organisms) is needed [3]. A strong adhesion depends on bonding surface treatment in order to improve a joint strength, although bond strength doesn't increase with increase of roughening [4]. The surface roughness modifications in the bonded area of the joint promote an expressive effect in the bonded structures $[5,6]$.

The main techniques for surface modification are sandblasting, grinding and chemical cleaning that makes a generation of specific surface topographies at bonding area. The advantages of bonding area preparation are a great mechanical coupling of the adhesive 
to the substrate and a good chemical compatibility of the polymer chains of the adhesive with substrate layers [7]. Parameters such as adhesive and substrate thickness have an important effect on efficiency of joints [8]. A decrease of joint strength with an increasing the adhesive layer is expected in epoxy adhesive joints $[9,10]$.

The important parameter of the bonded joint design is the influence of temperature and strain rate on the strength of the adhesive. The PolyAnchor $4100 \mathrm{HT}$ is a structural repair adhesive that response to elevated stress strength under extreme conditions below the temperature of glass transition, $T_{g}$, behaving as low-rigid material [11-13]. Composite repair standards such as ISO TS 24817 [14] and ASME PCC-2 [15] recommends a maximum application temperature as $T_{g}-30^{\circ} \mathrm{C}$.

Applications in harsh environments can speed up the degradation process. Air moisture is the main factor responsible for the decrease in the operational performance of structural adhesives. An accelerated the mechanical and chemical degradation phenomenon that results in reduction of adhesion strength, culminating in severe cases with a total separation of bonded joint [16]. The problems of single lap joint with humidity exposure were studied by Goglio et al. [17], the main defect mechanism was the presence of bubbles filled with water at primary substrate/adhesive layer modifying the surface bonding area and thus taunting the failure. Hydrothermal influence in adhesive bonded joints was observed by Soykok [18], considering the heat and moisture ageing process the maximum strength and stiffness of joints reduce by a significant value after a period of exposure at hot water.

Outdoor services are submitted to an incidence of ultraviolet radiation. Chemical modifications relating to UV exposure are effects of complicated process that involve UV radiation and oxygen. Despite of the Earth's act as a filter against the solar radiation about $6 \%$ of the total radiation of the Sun hit the Earth's surface [19].

The loss of properties starts with the interaction between photons coming to light that has a power with the initial discoloration until progressively to dissociate the structural chain of polymer material by means of short wavelengths (range from 290 to $400 \mathrm{~nm}$ ) with high energy [20, 21].

In the present work single lap joints were manufactured using three different surface preparations on the steel adherend, sandblasting, grinding and chemical cleaning. An epoxy system was used as an adhesive. After curing, single lap joints were submitted to UV radiation to simulate outdoor exposure. Then, after exposure, the joints were tested at room temperature and at elevated temperature to evaluate the influence of such degradation.

\section{Materials and methods}

\section{Materials}

The adhesive used in this work was an epoxy system named PolyAnchor 4100 HT provided by Polinova Ltd. It is a two-part resin system composed by Part A [diglycidyl ether of bisphenol A (DGEBA)] and Part B (mixture of polyamines, hardener). The system hardener mix ratio was 3:1 in volume. The properties of adhesive are presented in Table 1 . This type of polymer can be used in mechanical pipe repair with polymeric sleeve applications. PolyAnchor 4100 HT has high adhesion and is suitable to join metallic and non-metallic components in many sectors [12] 
Table 1 Properties of PolyAnchor 4100 HT epoxy resin [12]

\begin{tabular}{ll}
\hline Glass transition temperature $\left({ }^{\circ} \mathrm{C}\right)$ & 158 \\
Melting temperature $\left({ }^{\circ} \mathrm{C}\right)$ & 363 \\
Oxidation temperature $\left({ }^{\circ} \mathrm{C}\right)$ & 418 \\
Maximum tensile strength $\left(25^{\circ} \mathrm{C}\right)(\mathrm{MPa})$ & 23.12 \\
Maximum tensile strength $\left(115^{\circ} \mathrm{C}\right)(\mathrm{MPa})$ & 1.86 \\
\hline
\end{tabular}

Table 2 Properties 1020 carbon steel [22]

\begin{tabular}{ll}
\hline Young's modulus $(\mathrm{GPa})$ & 170 \\
Yield stress $(\mathrm{MPa})$ & 210 \\
Ultimate strength $(\mathrm{MPa})$ & 380 \\
Poisson's ratio & 0.3 \\
\hline
\end{tabular}

The adherend material of the lap joint is SAE 1020 carbon steel and its properties are shown in Table 2.

\section{Methods}

PolyAnchor 4100 HT single lap joints manufactured with three different surface preparation. Steel adherends were surface prepared by sandblasting, sanding and chemical cleaning. Before gluing the metal adherends, surfaces were blasted with sandgrit G25 at a nine bar pressure in an Air Blast machine. Each specimen was blasted at an angle of $45^{\circ}$ for $30 \mathrm{~s}$ and then cleaned with acetone. Sandpaper was used to perform the sanding surface preparation. Sandpaper 80 grit scratched the steel adherend surface in order to create a rough surface to provide a better adhesive anchorage. Last, just a chemical surface cleaning was performed to prepare the steel adherend surface, i.e. no abrasive method was used, just acetone surface cleaning. Previous to attaching steel adherends the roughness of the surface samples sandblasted, sanded and chemically cleaned was measured with a profilometer (Talysurf CCi Lite-Taylor Hobson). There are many roughness parameters bur Ra is by far the most common used. Ra is the arithmetic average of the roughness profile. Figure 1 presents the surfaces from the different preparations.

The results of profilometer measure were $\mathrm{Ra}=6.94 \mu \mathrm{m}$ for sandblasting, $\mathrm{Ra}=2.58 \mu \mathrm{m}$ for sanding and $\mathrm{Ra}=0.45 \mu \mathrm{m}$ for chemical cleaning.

After single lap joints fully cure, they were exposed ultraviolet (UV) rays for 6 months. The degradation chamber apparatus had a filtered xenon lamp (cut off $>290 \mathrm{~nm}$ ) and an irradiation of $0.3 \mathrm{~W} / \mathrm{m}^{2} / \mathrm{nm} @ 340 \mathrm{~nm}$. The radiation power used at $340 \mathrm{~nm}$ is in accordance to ASTM G155 [23]. Since specimens were in the UV chamber, they were inevitably heated.

The temperature inside the chamber was kept between 40 and $50{ }^{\circ} \mathrm{C}$. In this work, UV effects therefore include the effects of UV and the associated temperature effects induced by irradiation.

Mechanical tensile tests on the PolyAnchor 4100 HT single lap joint were performed using a Shimadzu ${ }^{\circledR}$ AG-X universal testing machine according to and ASTM D1002-10 [24]. Five samples were tested at a given condition (plain and UV exposed). 

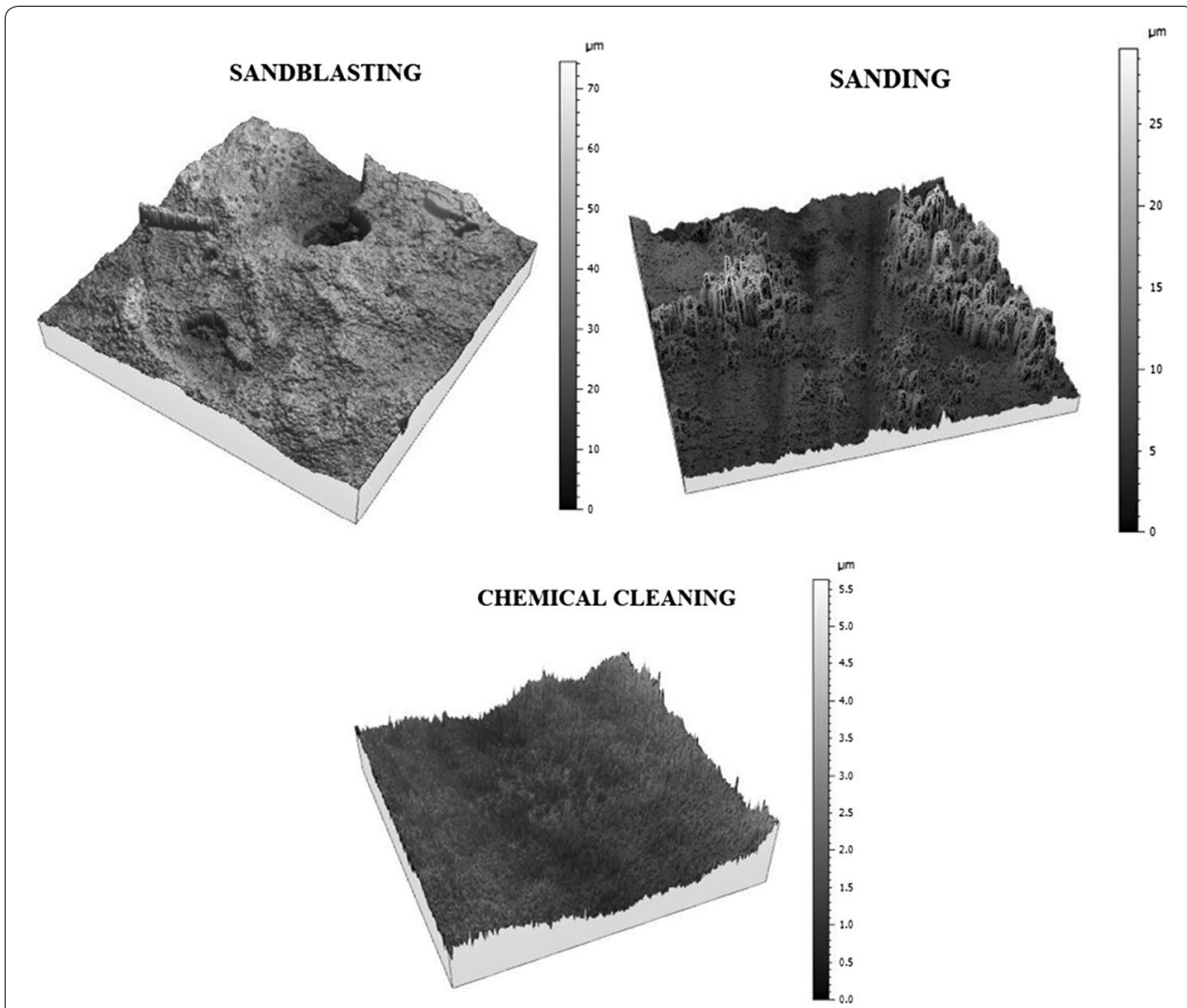

Fig. 1 Adherend surfaces from the different preparations

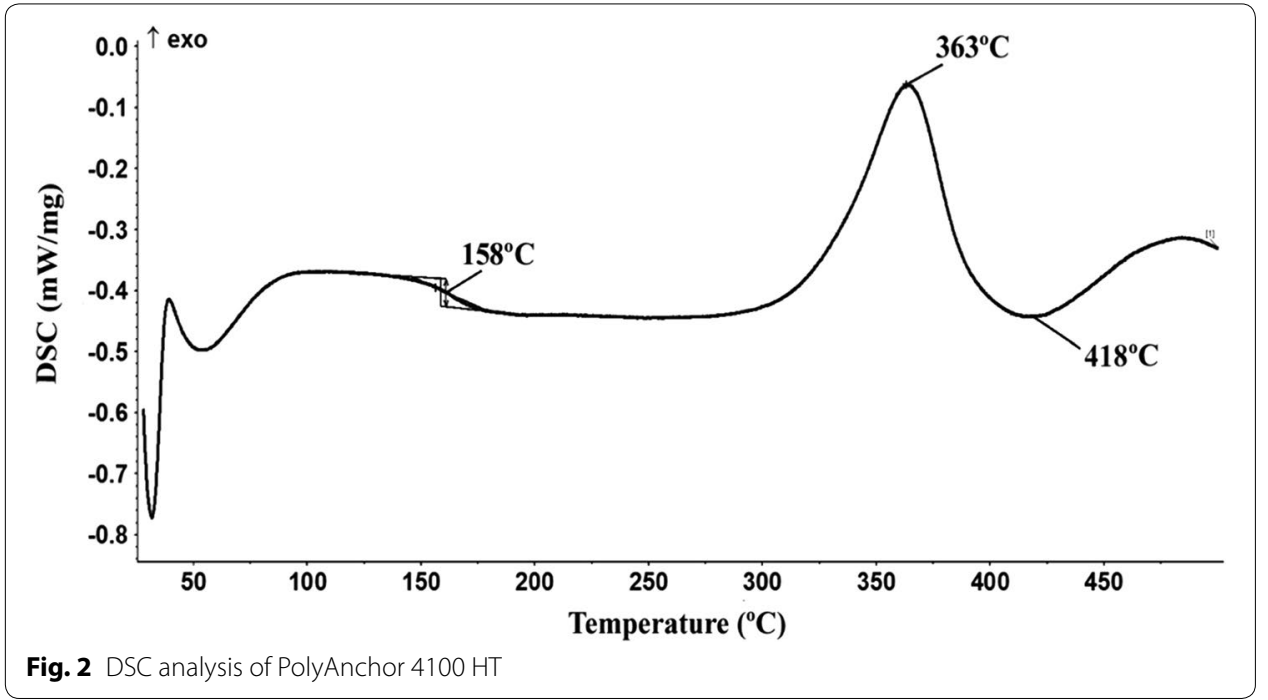

\section{Results and discussion}

\section{DSC analysis}

The differential scanning calorimetric test (DSC) of PolyAnchor 4100 HT before UV exposure is displayed in Fig. 2. 


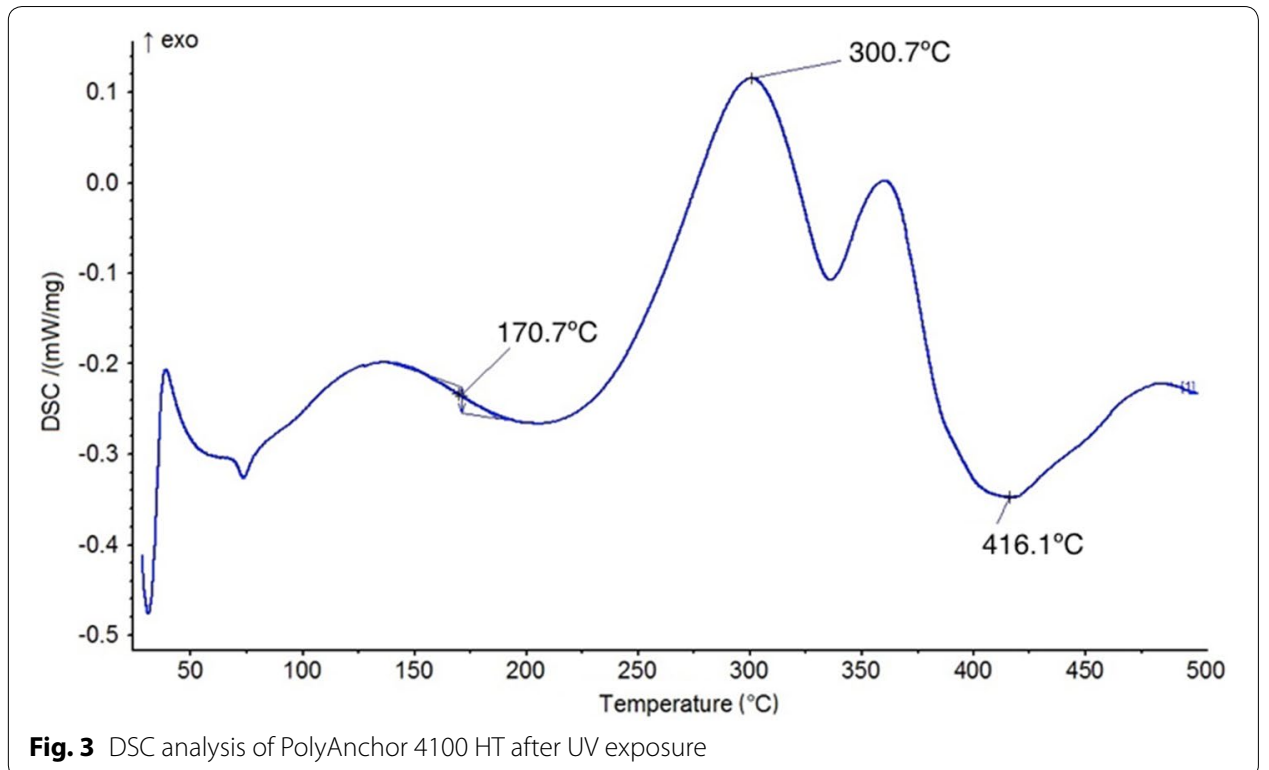

Table 3 Shear stress of adhesive bonded joint (avg. \pm st. dev)

\begin{tabular}{|c|c|c|c|c|}
\hline \multirow[t]{3}{*}{ Surface preparation } & \multicolumn{4}{|c|}{ Shear stress (MPa) } \\
\hline & \multicolumn{2}{|l|}{ Plain } & \multicolumn{2}{|l|}{ UV exposed } \\
\hline & $25^{\circ} \mathrm{C}$ & $115^{\circ} \mathrm{C}$ & $25^{\circ} \mathrm{C}$ & $115^{\circ} \mathrm{C}$ \\
\hline Sandblasting & $15.13 \pm 1.25$ & $5.89 \pm 0.67$ & $13.7 \pm 1.15$ & $14.44 \pm 1.58$ \\
\hline Sanding & $13.6 \pm 1.78$ & $3.08 \pm 0.02$ & $12.94 \pm 2.39$ & $12.53 \pm 1.64$ \\
\hline Chemical & $3.37 \pm 0.39$ & $2.77 \pm 1.55$ & $2.16 \pm 0.89$ & $3.40 \pm 1.23$ \\
\hline
\end{tabular}

From Fig. 2 it can be observed a glass transition temperature $\left(T_{g}\right)$ of $158{ }^{\circ} \mathrm{C}$. At this temperature epoxy system turns from a hard and relatively brittle "glassy" state into a viscous or rubbery state. The melting point $\mathrm{Tm}$ is at $363{ }^{\circ} \mathrm{C}$, where it happens an exothermic reaction. During the endothermic reaction, the decomposition occurs at $418^{\circ} \mathrm{C}$.

Figure 3 presents the differential scanning analysis of PolyAnchor $4100 \mathrm{HT}$ after UV exposure.

From Fig. 3 it can be observed a glass transition temperature $\left(T_{g}\right)$ around $170{ }^{\circ} \mathrm{C}$, melting temperature at $300.7{ }^{\circ} \mathrm{C}$ and oxidation temperature at $416.1{ }^{\circ} \mathrm{C}$. Comparing to nonexposed adhesive an increase in the glass transition temperature of $12.7^{\circ} \mathrm{C}$ is calculated. A significant decrease in melting point, $62.3^{\circ} \mathrm{C}$ is reported and oxidation temperature remains similar. Since the degradation process slowly heats the joints, it will contribute to increase mobility of polymer chain.

\section{Tensile tests on the single lap joints}

Table 3 presents the tensile tests performed on the single lap joints manufactured with PolyAnchor 4100 HT epoxy adhesive and different surface preparations.

It can be observed from Table 3 that surface preparation and temperature play an important role in the shear strength of polymer single lap joints. Higher surface 


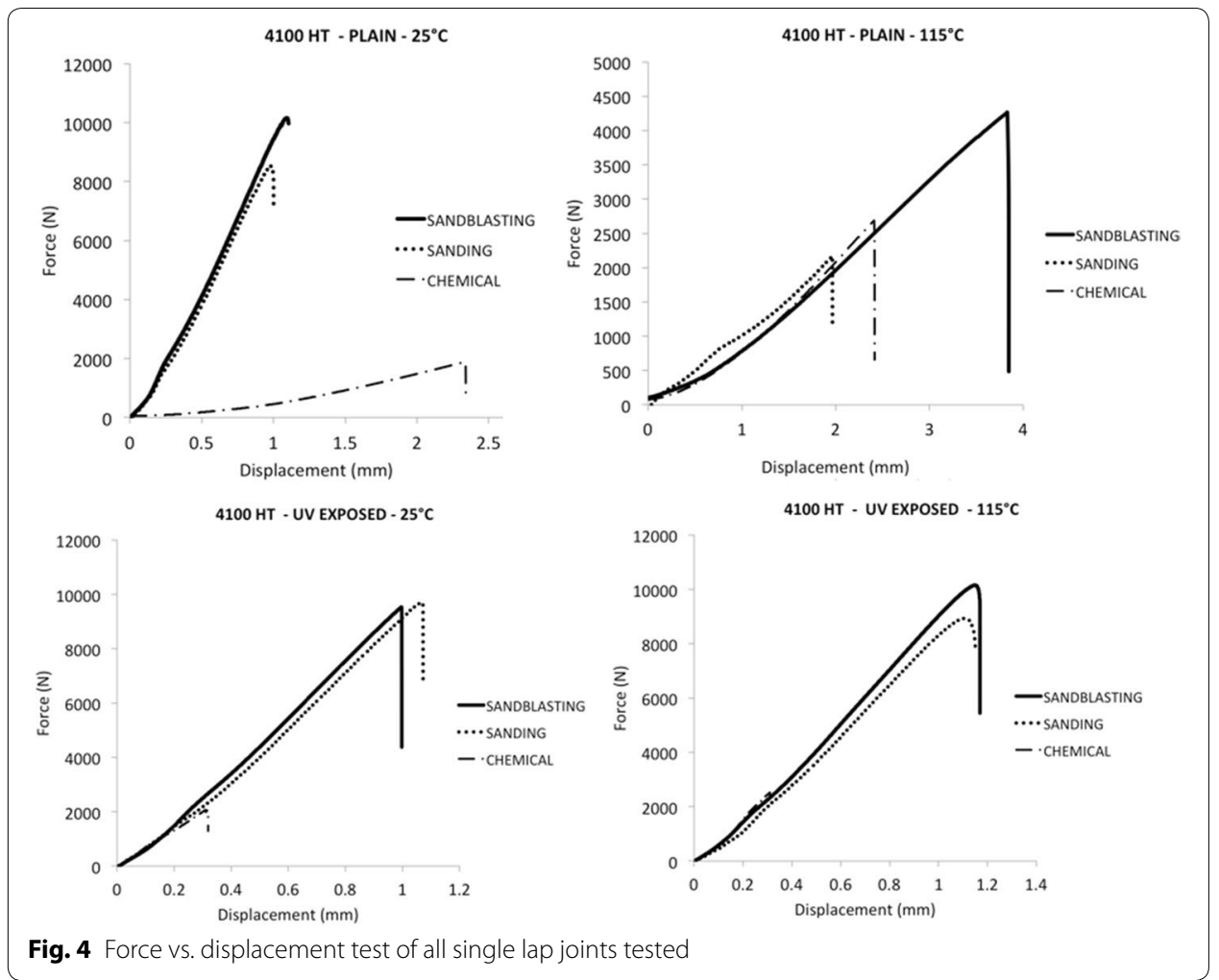

roughness produced a better adhesive anchorage and therefore elevated shear stress and elevated temperature lower shear strength. Sandblasting displays better surface roughness, then, sanding with sand paper and at last chemical cleaning. In all cases tested, for specimens without UV exposure, when the temperature increase from 25 to $115{ }^{\circ} \mathrm{C}$ a decrease in the shear strength is reported despite the surface preparation. When single lap joints were UV exposed and tested at elevated temperature, a slight increase in the shear strength is reported.

Analyzing the effect of UV exposure, at $25{ }^{\circ} \mathrm{C}$ occurs a decrease of $8.9,5$ and $35.9 \%$, respectively, in the shear strength when single lap joints were sandblasted, sanded and chemically cleaned, after UV exposure. For specimens tested at $115{ }^{\circ} \mathrm{C}$ occurs an increase of $145,306.8$ and $22.7 \%$ in the shear strength when single lap joints were sandblasted, sanded and chemically cleaned respectively after UV exposure. This can be explained by a post cure process of adhesive material, activated by UV irradiation. It will improve its mechanical properties by the photochemical modifications which promote a crosslinked network in the polymer. According previous work [25], ultraviolet exposure influences on the adhesive properties and the action of post cure process promotes an increase in mechanical strength.

The force-displacement curves for plain and UV exposed single lap adhesive joint bonded with PolyAnchor 4100 HT epoxy resin are presented in Fig. 4.

According to Fig. 4 it can be seen that the single lap joint tested at $25{ }^{\circ} \mathrm{C}$ with adherend chemical cleaned had a lower stiffness compared to the other lap joints tested at the same temperature condition. Stiffness of single lap joints manufactured with different surface preparation are not affected by high temperature. The same behavior is observed 


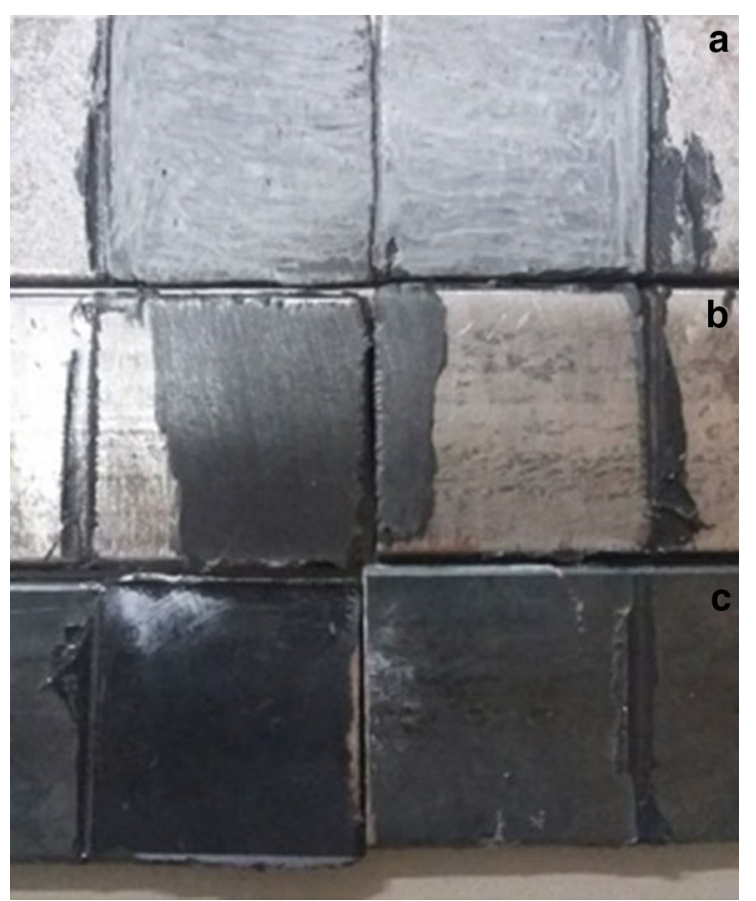

Fig. 5 Single lap joints failure modes. a Sandblasting, b sanding and $\mathbf{c}$ chemical cleaning

for specimens exposed to UV radiation, surface preparation does not affect the stiffness for both test temperatures. The elevation of temperature significantly affects maximum force. It also can be observed that sandblasting surface preparation produces a higher brake force and therefore higher shear strength, but it does not improve stiffness. Considering displacement, it is observed that for better surface preparation, sandblasting, higher joint displacement prior to UV exposure. Then, UV exposure contribute to single lap joints lower displacement compared to unexposed ones. The displacement of single lap joints exposed UV radiation is not affected by the temperature exposure producing similar joints stretch for all surface preparation analyzed.

Figure 5 presents the type of failure observed in single lap joints. The specimen A, with the sandblasting process presented cohesive failure, the joint $B$, with the sanding surface treatment presented mixed failure and sample $\mathrm{C}$, with the chemical surface cleaning present an adhesive failure. Thus, the sandblasting showed the most indicated surface treatment producing higher shear strength.

\section{Conclusions}

This research work studied the influence of UV exposure and temperature to adhesively bonded with different surface preparation, sandblasting, sanding and chemical cleaning. Single lap joints were exposed to UV radiation for 6 months and then tested at different temperatures, 25 and $115{ }^{\circ} \mathrm{C}$. Test results showed that surface preparation highly influences the shear strength, but does not affect the stiffness of the tested joints. Best results were produced by the sandblasted specimens which displayed higher surface roughness. Temperature also influences the shear strength and stiffness. UV radiation contributes to increase shear strength and do not degrade the tested single lap joints. It influences 
on the post curing process of the adhesive used increasing shear properties. These results contribute to improve adhesively joint engineering design for structural outdoor applications.

Authors' contributions

All authors contribute evenly for this work. All authors read and approved the final manuscript.

\section{Author details}

${ }^{1}$ Laboratory of Theoretical and Applied Mechanics, Graduate Program in Mechanical Engineering, Universidade Federal Fluminense, Rua Passo da Pátria 156, Niterói, RJ 24210-240, Brazil. ${ }^{2}$ Department of Mechanical Engineering, Federal Center for Technological Education of Rio de Janeiro, CEFET-RJ, UnED, Itaguaí, RJ, Brazil.

\section{Acknowledgements}

The authors thank the Research Foundation of the State of Rio de Janeiro (FAPERJ), the Brazilian National Council for Scientific and Technological Development (CNPq) and Coordination for the Improvement of Higher Education Personnel (CAPES) for supporting part of the work presented here.

\section{Competing interests}

The authors declare that they have no competing interests.

Availability of data and materials

Data will not be shared due to adhesive manufacturer police.

Ethics approval and consent to participate

Not applicable.

Funding

No funding was received.

\section{Publisher's Note}

Springer Nature remains neutral with regard to jurisdictional claims in published maps and institutional affiliations.

Received: 3 May 2018 Accepted: 21 May 2018

Published online: 25 May 2018

\section{References}

1. da Costa Mattos HS, Sampaio EM, Monteiro AH. A simple methodology for the design of metallic lap joints bonded with epoxy/ceramic composites. Compos Part B Eng. 2012;43:1964-9.

2. Fernandes TAB, Campilho RDSG, Banea MD, da Silva LM. Adhesive selection for single lap bonded joints: experimentation and advanced techniques for strength prediction. J Adhes. 2015;91:841-62.

3. Ghumatkar A, Budhe S, Sekhar R, Banea MD, de Barros S. Influence of adherend surface roughness on the adhesive bond strength. Lat Am J Solids Struct. 2016;13:2356-70.

4. Azari S, Papini M, Spelt JK. Effect of surface roughness on the performance of adhesive joints under static and cyclic loading. J Adhes. 2010;86:742-64.

5. Costa HRM, Reis JML, Souza JPB, Pacheco PMCL, Aguiar RAA, de Barros S. Experimental investigation of the mechanical behaviour of spot welding-adhesives joints. Compos Struct. 2015;133:847-52

6. de Barros S, de Souza JR, Gomes KC, Sampaio EM, Barbosa NP, Torres SM. Adhesion of geopolymer bonded joints considering surface treatments. J Adhes. 2012:88:364-75.

7. Baburaj EG, Stariko D, Evans J, Shafeev GA, Bensaoula A. Enhancement of adhesive joint strength by laser surface modification. Int J Adhes Adhes. 2007:27:268-76.

8. Costa RRC, Medeiros R, Ribeiro ML, Tita V. Experimental and numerical analysis of single lap bonded joints: epoxy and castor oil PU-glass fiber composites. J Adhes. 2017;93:77-94.

9. de Barros S, Kenedi PP, Ferreira SM, Budhe S, Bernardino AJ, Souza LFG. Influence of mechanical surface treatment on fatigue life of bonded Joints. J Adhes. 2017;93:599-612.

10. Banea MD, da Silva LFM, Campilho RDSG. The effect of adhesive thickness on the mechanical behavior of a structural polyurethane adhesive. J Adhes. 2015;91:331-46.

11. Banea MD, de Sousa FSM, da Silva LFM, Campilho RDSG, de Bastos Pereira AM. Effects of temperature and loading rate on the mechanical properties of a high temperature epoxy adhesive. J Adhes Sci Technol. 2011;25:2461-74

12. Reis JML, Amorim FC, da Silva AHMFT, da Costa Mattos HS. Influence of temperature on the behavior of DGEBA (bisphenol A diglycidyl ether) epoxy adhesive. Int J Adhes Adhes. 2015;58:88-92.

13. Souza JPB, Reis JML. Thermal behavior of DGEBA (Diglycidyl Ether of Bisphenol A) adhesives and its influence on the strength of joints. Appl Adhes Sci. 2013. https://doi.org/10.1186/2196-4351-1-6.

14. ISO/TS 24817-2006. Petroleum, petrochemical and natural gas industries-composite repairs for pipework-qualification and design, installation, testing and inspection. 2006.

15. ASME PCC-2-2011. Repair of pressure equipment and piping. 2011.

16. Lefebvre DR, Takahashi KM, Muller AJ, Raju VR. Degradation of epoxy coatings in humid environments the critical relative humidity for adhesion loss. J Adhes Sci Technol. 1991;5:201-27.

17. Goglio L, Rezaei M. Degradation of epoxy-steel single lap joints immersed in water. J Adhes. 2015;91:621-36. 
18. Soykok IF. Degradation of single lap adhesively bonded composite joints due to hot water ageing. J Adhes. 2017;93:357-74

19. XuT, Li G, Pang S. Effects of ultraviolet radiation on morphology and thermo-mechanical properties of shape memory polymer based syntactic foam. Compos Part A Appl S. 2011;42:1525-33.

20. Nguyen T, Bay Y, Zhao X, Al-Mahaidi R. Effects of ultraviolet radiation and associated elevated temperature on mechanical performance of steel/CFRP double strap joints. Compos Struct. 2012;94:3563-73.

21. Shokrieh MM, Bayat A. Effects of ultraviolet radiation on mechanical properties of glass/polyester composites. J Compos Mater. 2007;41:2443-55.

22. da Costa Mattos H, da Silva Nunes LC, Monteiro AH. Load rate effects in adhesive single lap joints bonded with epoxy/ceramic composites. Lat Am J Solids Struct. 2016;13:1878-92.

23. ASTM G155-13. Standard practice for operating xenon arc light apparatus for exposure of non-metallic materials. 2013.

24. ASTM D1002-10. Standard test method for apparent shear strength of single-lap-joint adhesively bonded metal specimens by tension loading (metal-to-metal), Pennsylvania, United States. 2010.

25. Sousa JM, Correa JR, Cabral-Fonsea S. Durability of an epoxy adhesive used in civil structural applications. Constr Build Mater. 2018;161:618-33.

Submit your manuscript to a SpringerOpen ${ }^{\circ}$ journal and benefit from:

- Convenient online submission

- Rigorous peer review

- Open access: articles freely available online

- High visibility within the field

- Retaining the copyright to your article

Submit your next manuscript at $\mathbf{s p r i n g e r o p e n . c o m ~}$ 